\title{
ROLE OF DISCRETE NATURE OF CHIP FORMATION AND NATURAL VIBRATIONS OF SYSTEM COMPONENTS IN CHATTER FORMATION DURING METAL CUTTING
}

\author{
A. K. M. Nurulamin*, I. H. JaAfar, A. U. Patwari And \\ W. W. D. ZUBAIRE \\ Department of Manufacturing and Materials Engineering, Faculty of Engineering, \\ International Islamic University Malaysia, Jalan Gombak, 53100 Kuala Lumpur, Malaysia, \\ *E-mail:akamin@iiu.edu.my
}

\begin{abstract}
In the present work a review of the existing theories of chatter formation has been conducted and the weaknesses of the most widely accepted 'Regenerative Chatter theory' in explaining various phenomena related to chatter formation have been identified. An attempt has been made in this work to determine the common causes of chatter formation in different metal cutting operations, namely, turning, thread cutting and end milling conducted on plain carbon steel AISI 1040. Experimental investigations have been conducted during the above types of machining processes to identify the marks of instability and chatter on the formed chips. It has been identified that in all the three machining operations the chips formed show a common type of discreteness in the form of secondary saw teeth, which appear at the free edge of the chip. Mechanism of formation of these teeth has been studied and the frequencies of their formation have been determined for different cutting conditions. Apart from the secondary saw teeth primary saw teeth have also been identified at the main section of the chip and their frequencies were also determined. At the same time the natural vibrations of the main system components have been identified and the acceleration amplitudes at the prominent natural frequencies during actual machining were recoded using a dedicated vibration monitoring system. The frequencies of secondary chip serration and the natural frequencies of the system components were plotted against cutting speed. Acceleration amplitudes at the prominent natural frequencies were also plotted separately against cutting force. Based on comparison and analysis of these two frequency and amplitude graphs it was concluded that chatter (vibration with relatively high amplitude) appears in the system when the frequency of secondary saw teeth approaches values equal to half or integer multiple of a prominent natural frequency of the system resulting in resonance. In the case of thread cutting and turning the main vibrating component was identified as the tool holder and in the case of end milling the main vibrating components were the tool holder and the spindle. Severe vibration/chatter was found to appear during end milling when the tool and the spindle simultaneously entered into resonance. This occurred when the chip serration frequency got close to the spindle's natural frequency, which was approximately twice the value of the natural frequency of the tool holder in the conducted experiments.
\end{abstract}

KEYWORDS: Chip formation instability, secondary saw teeth, natural frequencies, resonance and chatter. 


\section{INTRODUCTION}

Chatter is defined the self-excited violent relative dynamic motion between the cutting tool and work piece. It is an undesirable but sometimes unavoidable phenomenon in metal cutting. It has adverse effects on the product quality, operation cost, machining accuracy, output and machine-tool life. It is also responsible for reducing output. The main characteristic of machine tool chatter is its self-induced nature, not caused by external periodic forces. Although chatter has been extensively investigated in the past 40 years, the root cause of chatter still remains debatable. Taylor suggested that element chip formation is responsible for chatter [1], but this proposition was not acceptable since element chip formation occurs at extremely low cutting speed where chatter is seldom observed. Kuznetsov considered that the periodic effect of built-up-edge (BUE) formation can excite vibration [2]. Kudinov [3] and Shteinberg [4] also considered that the vibration caused by the unstable and periodically broken BUE is responsible for chatter. However, again no serious chatter is observed in the cutting speed range with BUE formation and chatter generally exists at relatively higher cutting speeds where BUE is absent. Doi [5], Doi and Kato [6], and later Kato [7] stated that chatter was established primarily due to a phase lag of the cutting force with respect to the fluctuation of chip thickness. Nevertheless, Smith [8] and later Smith and Tobias [9] suggested on the findings of Doi and Kato that, the force phase lag was primarily related to the low frequency of vibration. It was found by them that as the vibration frequency increased, the phase difference decreased, and at higher frequencies the force fluctuations even preceded the fluctuation of the chip thickness. Doi and Kato [6] proposed the regenerative chatter theory, according to which vibration marks on the work piece left from the previous cuts is responsible for chatter in the subsequent cuts. The latter has found overall acceptance in the metal cutting research community and is often referred to in numerous models developed to simulate the chatter phenomenon. According to the Regenerative theory, chatter arises in the system as result of the waviness left from the previous cut which the tool follows in the subsequent cut. Appearance of chatter and stable cutting are thought to be the result of offsetting and coincidence of phase of the previous and the current waviness. However, based on experimental results, Amin [10-12] concluded that waviness on the cutting/job surface is not the cause of chatter, rather it's after effect. He also observed that chatter occurred at nearly constant frequencies, close to the natural frequencies of prominent system components over a range of cutting speed for a given set of cutting conditions, which can not be explained by the Regenerative Chatter theory. Apart from that initial tests conducted on helical turning i.e. thread cutting, show that there is gradual amplification of vibrations which occur at constant frequencies, close to the natural frequency of the spindle and the tool holder similar to the case of turning, though there is no previous waviness which the tool is following. Regenerative Chatter theory again has no explanation for the amplification of vibration amplitudes in this particular cutting operation. Amin observed a type of serrated teeth at the free edge of the chip found that when the frequency of formation of these chips coincided with the natural frequency of a system component, chatter appeared during the cutting operation as a result of resonance. Similar results were found by Israd [13] during room temperature end milling and also by Amin and Abdelgadir [14, 15] during preheated end milling operations of mild steel and stainless steels. It is therefore essential to know whether the formative mechanisms of chatter during end milling, turning and thread cutting are similar in these three diversified processes involving interrupted and continuous cutting. In the first two of the above 
processes the tool follows the traces of the previous chatter marks, but in the last operation the tools cuts though fresh material without following the traces of chatter marks of the previous cut. Commonness of the mechanism would prove beyond doubt that chatter appears in the system not due to the 'regenerative' effect (following chatters marks left from the previous cut) but due to some other mechanism, may be due to the resonance effect, as proposed by Amin.

Studies conducted by Altintas and others [16-19] contributed to understanding of chatter in end milling operations. Altintas developed the chatter dynamic models. Mann et al [20] also studied on the stability and chatter frequency characteristics. For determining the type of instability of the periodic motion of this nonlinear, non-homogeneous, nonautonomous, delay-differential system, numerical schemes with an analytical basis are required. In their work, [21, 22] Insperger and Stépán have improved the semidiscretization method to examine the stability of periodic solutions of systems with two time delays. Long and Balachandran [23] worked with systems with variable time delay. The present work has the following objectives:

1. To verify the presence of secondary saw teeth at the free side(s) of the chip during turning, thread cutting and end milling and to determine the frequency their formative cycle.

2. To determine the role of the secondary chip serration frequency in chatter formation in the three proposed machining processes.

3. To study the frequency-amplitude characteristics of vibration/chatter under variable cutting and system parameters to investigate whether there is any common mechanism of chatter formation in these three different machining processes.

\section{EXPERIMENTAL SETUP AND METHODOLOGY}

\subsection{Experimental Setup}

The main thrust of the experiments was on the study of chips and monitoring of vibrations during different types of machining operations, involving different machine tools and fixture systems. For studying the chips, scanning electron microscope (SEM), optical microscope and a digital camera were used. For monitoring the vibration a specially designed data acquisition system was used. Datalog DASYLab 5.6 was used for signal analysis and processing. The main software modules used are the amplitude-time display (time domain), the FFT display (frequency domain). Frequency range of interest was $0-10,000 \mathrm{~Hz}$. The Fast Fourier Transform, or the FFT, was used for changing the signals from the time to the frequency domain using the power density spectrum.

Turning and threading operations were conducted on lathe machine of model Harrison M600. The schematic illustration of the experimental setup used in turning and threading operations is shown in Fig. 1a. SANDVIK made inserts of code number: CNMG 120408 WM were fitted onto a tool holder of code number: PCLNR 2525M12 were used for both these operations. Three different overhang values of the tool holder: 40, 50 and $60 \mathrm{~mm}$, were used to introduce a variation in the elastic system parameters. Investigations for all the three machining operations were conducted on carbon steels AISI 1040. Cutting 
parameters used for turning were: Cutting speed $=50-350 \mathrm{~m} / \mathrm{min}$, at an interval of 50 $\mathrm{m} / \mathrm{min}$, depth of cut $=2 \mathrm{~mm}$ and feed $=0.1 \mathrm{~mm} /$ rot.

During thread cutting/helical turning the compound rest was inclined to ensure equal side and auxiliary cutting edge angles. The tool holder was clamed with an overhang value of $50 \mathrm{~mm}$. Cutting speeds were in the range $2.5-18 \mathrm{~m} / \mathrm{min}$, at an interval of approximately $2 \mathrm{~m} / \mathrm{min}$ and depth of cut was $1.0 \mathrm{~mm}$. The feed (pitch) value was maintained above $2.5 \mathrm{~mm}$ so that the tool did not follow the previous cut. Fig. 1b presents the schematic illustration of the experimental setup used in the end milling operation. End milling tests were conducted on vertical machining center modeled ZPS 1060. All the cutting operations involved the use of an end mill cutter (SANDVIK CoroMill R390). The overhanging length of the tool holder was $63 \mathrm{~mm}$ and the diameter $20 \mathrm{~mm}$. The number of inserts used at a time was varied between 1,2 , or 3 .

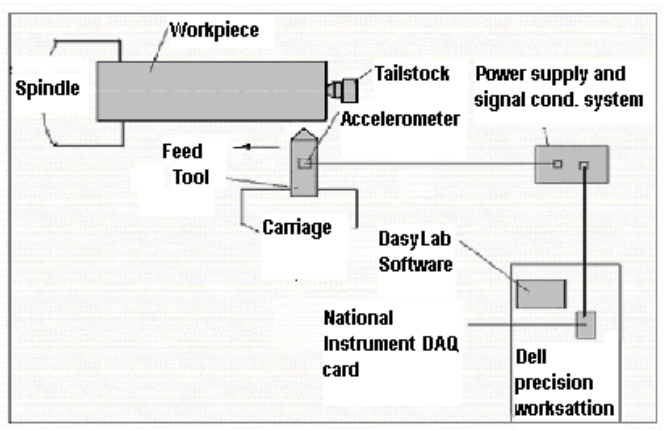

(a)

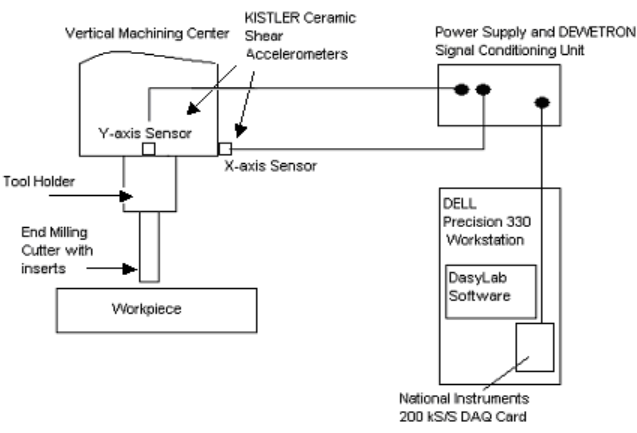

(b)

Fig. 1: Schematic diagrams of the experimental setup used in: (a) plain and helical turning and (b) end milling.

The inserts chosen were SANDVIK Coromat PM 4040 TiN coated carbide. Study was also conducted on chips generated during end milling using circular inserts under preheated and non preheated conditions to investigate the chip behaviour under those extreme cutting conditions. The workpiece material used in the experiment was medium carbon steel AISI 1040. Depths of cut were 1 and $2 \mathrm{~mm}$ and feed rate $0.2 \mathrm{~mm} /$ tooth.

\subsection{Experimental Procedures}

\subsubsection{Free Vibration}

Free vibration analysis of the relevant components of the machine-tool-job-fixture system was conducted for both lathe and milling machines. A forced excitation is given to the system using a plastic mallet. The free vibration data were sensed by an accelerometer attached to the element opposite to the point of impact. The free vibration response is observed in the frequency domain. Peak amplitudes denoted resonance of the system's natural frequencies. 


\subsubsection{Chip Analysis}

In order to have a close look at the chip to identify the presence of the primary and the secondary saw teeth and any other type of instability that might be present in the outer view of the chip, the latter was viewed under a scanning electron microscope (SEM). The frequency of the secondary saw teeth formation, $F_{c}$, was calculated knowing the length of the portion of the chip in the SEM picture, $L$, the coefficient of chip shrinkage, $K$, cutting speed, $V \mathrm{~m} / \mathrm{min}$ and the number of secondary saw teeth, $n$, observed on the SEM picture; using the following formula:

$$
F_{c}=1000 \frac{n V}{60(L K)}[\mathrm{Hz}]
$$

\section{RESULTS AND DISCUSSION}

\subsection{Free Vibration}

Samples of free vibration analysis of the relevant components of the machine-tool-jobfixture system for both lathe and milling machines are shown in Fig. 2 (a) for lathe tool and Fig. 2 (b) for VMC tool-chuck system. The natural frequencies of the lathe machine system are listed in Table 1 and those for the VMC in Table 2.

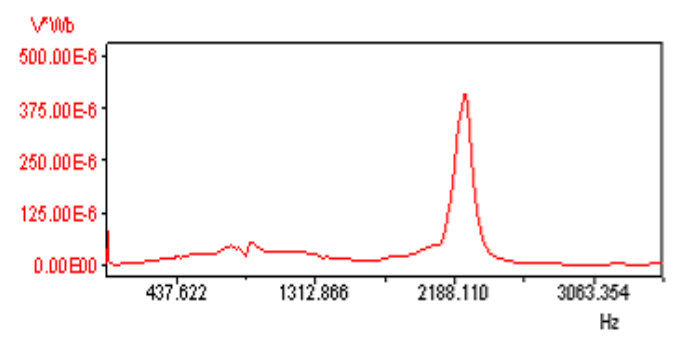

(a)

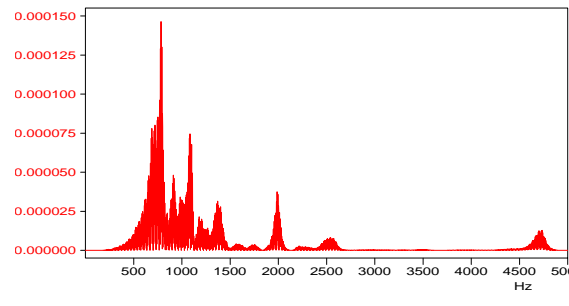

(b)

Fig. 2: Samples of FFT plot of the natural frequencies for the system components: (a) for the tool and chuck system of VMC and (b) the tool holder of $60 \mathrm{~mm}$ overhang in lathe.

Table 1: Natural frequency of the lathe machine system.

\begin{tabular}{|c|c|c|c|c|c|c|c|}
\hline \multirow{2}{*}{$\begin{array}{c}\text { System } \\
\text { Component }\end{array}$} & \multicolumn{3}{|c|}{$\begin{array}{c}\text { Tool holder } \\
\text { with overhang, } \mathrm{mm}\end{array}$} & \multirow{2}{*}{ Carriage } & \multirow{2}{*}{$\begin{array}{c}\mathrm{W} / \mathrm{p}- \\
\mathrm{SS}\end{array}$} & \multirow{2}{*}{$\begin{array}{c}\mathrm{W} / \mathrm{p} \\
\text {-AISI } 1040\end{array}$} & \multirow{2}{*}{ Spindle } \\
\hline & 40 & 50 & 60 & & & & \\
\hline $\begin{array}{c}\text { Approximate } \\
\text { natural } \\
\text { frequency, }(\mathrm{Hz})\end{array}$ & 2705 & 2475 & 2250 & 1760 & 158 & 150 & 870 \\
\hline
\end{tabular}


Table 2: Natural frequency of the different components of the vertical machining center (VMC).

\begin{tabular}{|c|c|c|c|c|}
\hline $\begin{array}{c}\text { System } \\
\text { Component }\end{array}$ & $\begin{array}{c}\text { Chuck, } \\
\mathrm{Hz}\end{array}$ & $\begin{array}{c}\text { Tool holder, } \\
\mathrm{Hz}\end{array}$ & $\begin{array}{c}\text { Tool (63 mm } \\
\text { overhang) } \mathrm{Hz}\end{array}$ & $\begin{array}{c}\text { Spindle, } \\
\mathrm{Hz}\end{array}$ \\
\hline $\begin{array}{c}\text { Approximate } \\
\text { natural } \\
\text { frequency, }(\mathrm{Hz})\end{array}$ & 795 & 2000 & 2540 & 4700 \\
\hline
\end{tabular}

\subsection{Analysis of Chips Produced during Turning}

A sample of SEM view of the chip formed during turning is shown in Fig. 3. The presence of the secondary saw teeth at one side of the chip can be observed from the figure. Apart from the secondary saw teeth deformation of grain (as indicated in the figure) at frequency higher compared to the secondary tooth serration frequency, can also be observed in the same figure. From Fig. 3, the following observations were made on instability of chip formation during turning:

1. Chip formation is unstable because of the formation of secondary saw/saw teeth which are regularly spaced and located at free edge of the chip (at the edge opposite to the location of the tool nose).

2. Apart from these relatively larger saw teeth, marks of grain shear running across the whole width of the chip are also observed. These are also termed as primary saw teeth. A certain number of these minute sheared grains combine to form a large secondary saw tooth.

3. Cracks are observed at the boundary between two adjacent secondary saw teeth.

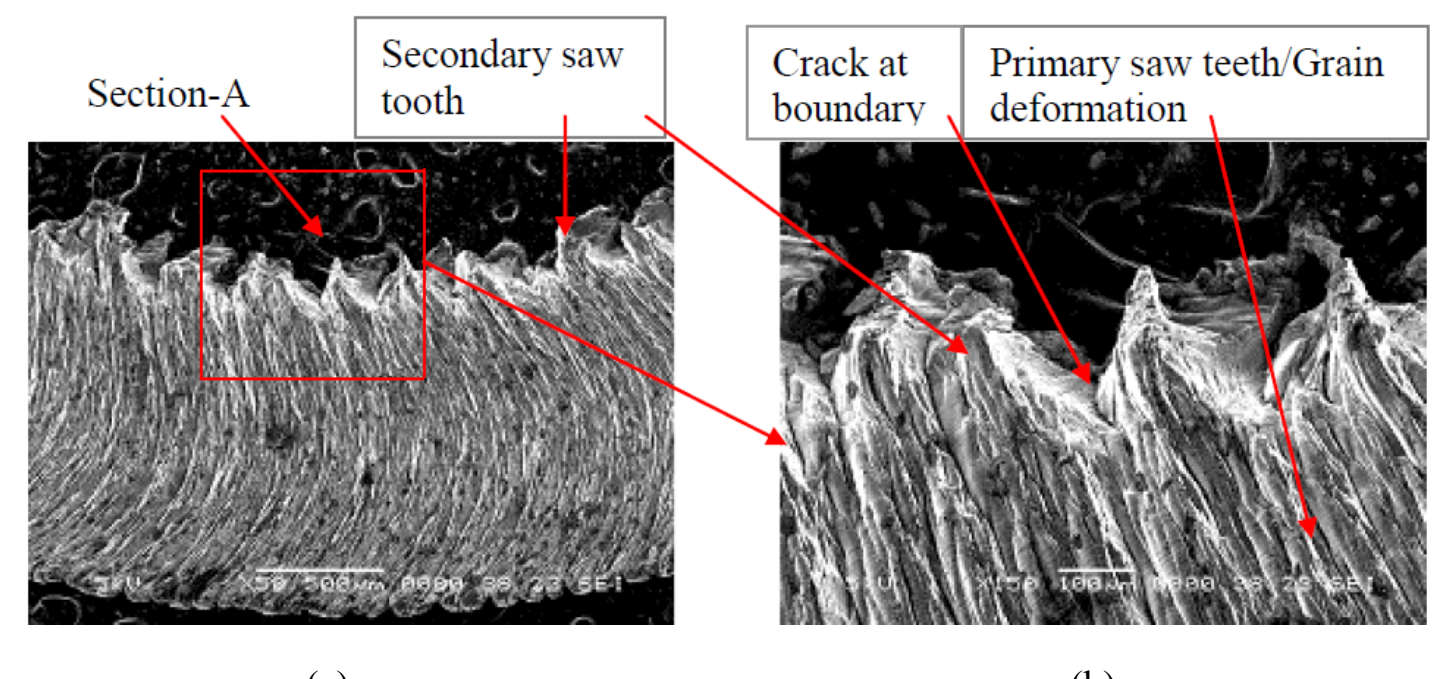

(a)

(b)

Fig. 3: Sample of the SEM view of the top surface of chips formed during turning of plain carbon steel AISI 1040 at cutting speed of $350 \mathrm{~m} / \mathrm{min}$, at depth of cut of $2 \mathrm{~mm}$ and feed rate of $0.1 \mathrm{~mm} / \mathrm{rev}$ : (a) at 50x, and (b) at $150 \mathrm{x}$ for section $\mathrm{A}$. Tool overhang value $=60$ $\mathrm{mm}$. 


\subsection{Analysis of Chip Produced during Thread Cutting}

Experiments on thread cutting were conducted to verify the presence of secondary saw teeth in the chip and their influence on system vibration and chatter. Samples of the SEM top views of the chips are shown in Fig. 4. Following observations are made from the views of chips formed during helical turning/thread cutting similar to the one shown in Fig. 4:

1. Saw teeth are observed along both the (lengthwise) edges of the chip. In this operation cutting is performed by both the cutting edges of the tool and hence there are two free edges of the chip along which secondary saw teeth are formed.

2. The appearance and the mechanism of formation of these secondary saw teeth are similar to those formed during outer turning operation, as illustrated in Fig. 4. But since these elements are formed at very low speeds, at which the material undergoes more of strain hardening and less of temperature softening or annealing, cracks appear not only at the boundary lines of the secondary saw teeth but also at the shear boundaries of individual grain (Fig. $4 \mathrm{a}, \mathrm{b}$ ).

3. The number of saw teeth per unit length of chip is found to increase with cutting speed (Fig. 4 a, b).

\subsection{Analysis of Chips produced in End Milling}

The chips formed during end milling using rectangular and circular inserts were mainly investigated and it has been found that in the case of circular inserts chip formation presents extreme case of secondary and primary chip serration especially at certain specific cutting conditions. Typical SEM pictures and micro-sections of chips formed under various conditions were also studied. Some sample pictures are shown in Fig. 5, 6.

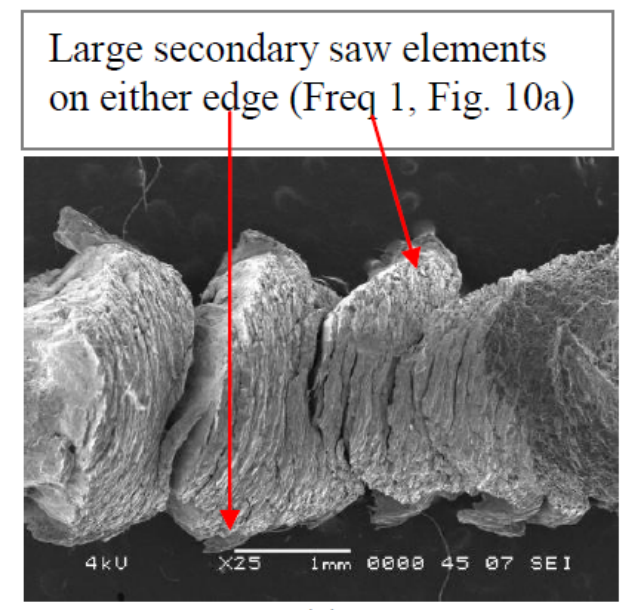

(a)

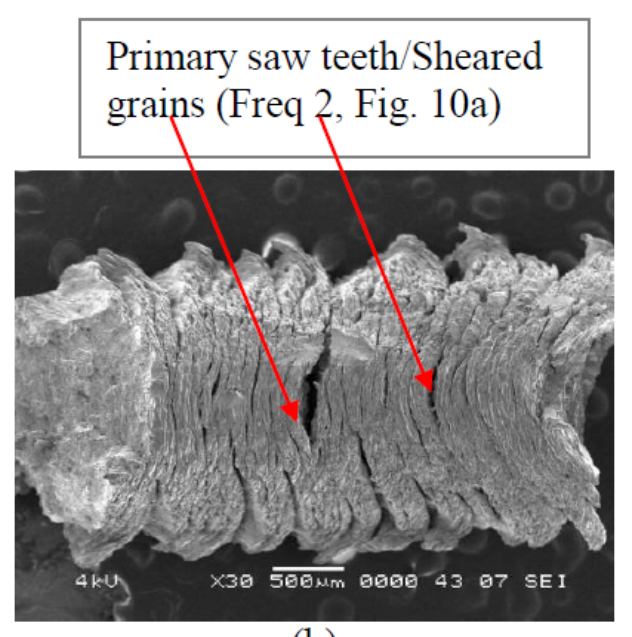

(b)

Fig. 4: Samples of the SEM top views of the chips produced during helical turning cutting of a shaft of carbon steel AISI 1040 at depth of cut of $1 \mathrm{~mm}$ and feed rate of $10 \mathrm{~mm} / \mathrm{rev}$ at cutting speeds: (a) $\mathrm{V}=2.5 \mathrm{~m} / \mathrm{min}$ and (b) $\mathrm{V}=$ $10.9 \mathrm{~m} / \mathrm{min}$. 


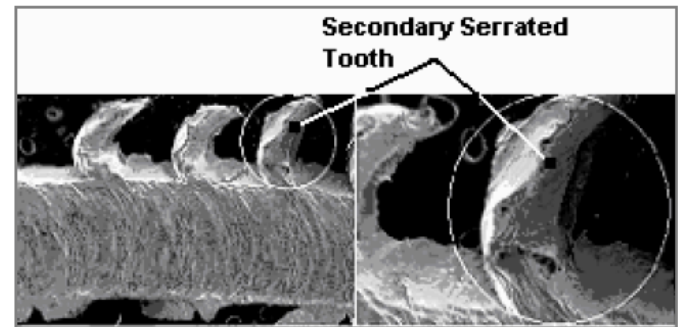

(a)

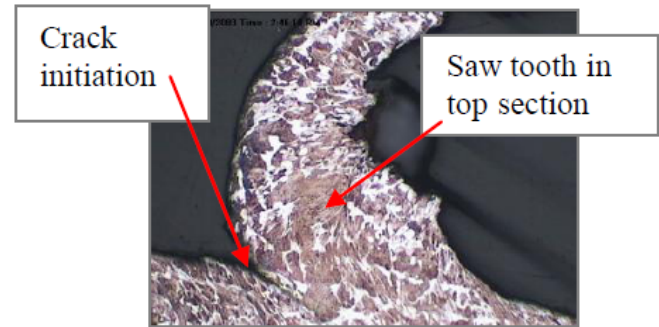

(b)

Fig. 5: SEM top views of the chip formed during end milling using prismatic inserts: (a) top views at different magnifications, and (b) enlarged top sectional view of a saw tooth.

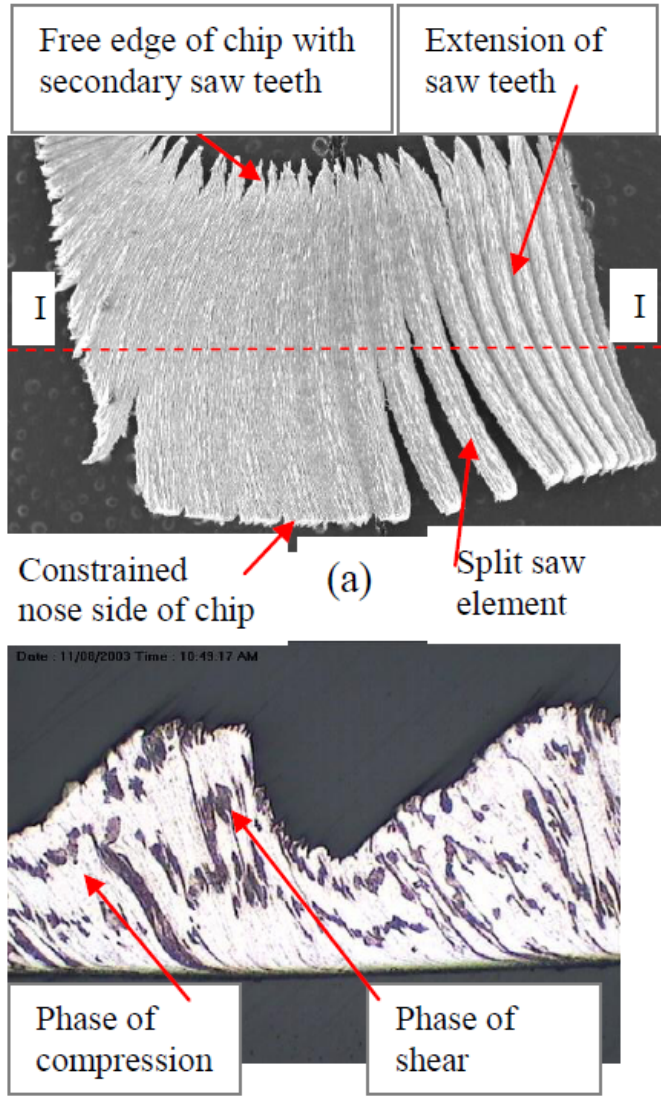

(c)

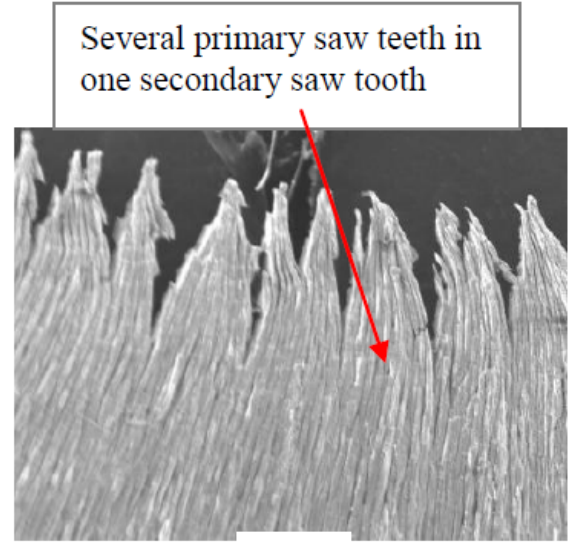

(b)

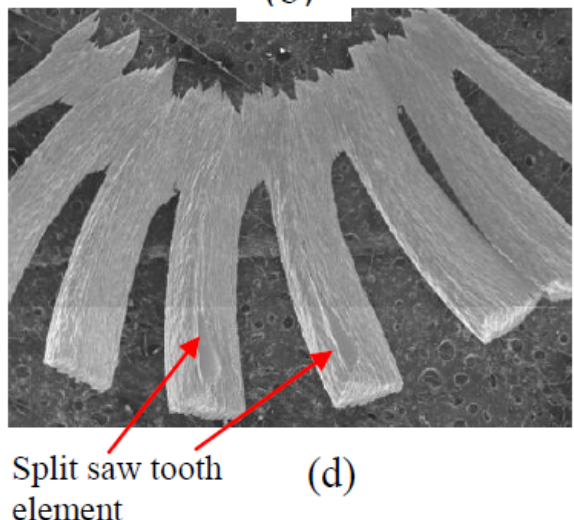

Fig. 6: Views of chip formed during end milling with circular inserts: (a-c) at $50 \mathrm{~m} / \mathrm{min}$ applying workpiece preheating, (d) at speed of $250 \mathrm{~m} / \mathrm{min}$ room temperature cutting, (b) enlarged view of saw elements of (a), (c) micro section of the chip along line I-I shown in (a). Cutting conditions: Feed rate $=0.1 \mathrm{~mm} /$ tooth and depth of cut $=1 \mathrm{~mm}$. 
The following observations are made from Fig. 5, 6:

Chips formed in end milling using prismatic inserts are continuous with the presence of secondary saw teeth. The saw teeth are formed along the free edge of the chip at almost equal spacing. The top sectional view (Fig. 5 b) of a saw element shows the presence of directional flow of the deformed material.

Chips formed in end milling using circular inserts are very much saw in nature with the presence of secondary saw teeth running along the entire width of the chip. Several sheared grains are found to combine into a relatively larger secondary saw element at the free edge of the chip (Fig. 6 a, c, d).

In some cases the chips get segregated into needle shaped elements loosely joined together at one of the edges (Fig. 6a,b,d), especially during preheated end milling using circular inserts and also at higher cutting speeds during room temperature machining (Fig. 7d). This phenomenon indicates the tendency of the chip to get separated into discrete elements along the boundary lines between two neighboring secondary saw teeth.

Hence it may be also concluded from here that secondary saw teeth formation is the outcome of the inherent discreteness of the chip formation process. Cross sectional view of the chip (Fig. 6c) reveal that the mechanism of formation of saw teeth is similar to that in turning, in which each chip element undergoes alternate phases of compression and shear.

It can be concluded from the above analyses of chips that the mechanisms of chip formation in turning, thread cutting and end milling are very similar with minor differences. In all these cases, the chip formation process is accompanied with inherent instabilities and the tendency to form primary and secondary saw teeth. Several primary saw teeth combine to form a secondary serrated tooth ultimately may lead to the formation of discrete elements. The secondary saw teeth lead to the formation of discrete chip elements or loosely bound segmented chips under severe cutting deformation conditions as in the case of end milling conducted with circular inserts.

\subsection{Relationship between the Frequency of Secondary Saw Teeth and Vibration /Chatter in Turning and Thread Cutting}

In this section the frequencies of secondary saw teeth were compared with the chatter frequency and amplitude at different cutting speeds to identify the relationship among these parameters. For recording the vibration data, a single sensor was mounted at the lower surface of the tool holder, as mentioned earlier. FFT output in power spectrum were analyzed and the highest acceleration amplitude peaks and the corresponding excited frequencies at every cutting condition were recorded for both the operations. Typical FFT output in power spectrum for plain turning is shown in Fig. 7 and that for thread cutting in Fig. 8. It can be observed from these two figures and Table 1 that the most significant vibrations in the cases of turning and thread cutting correspond to the vibrations of the tool holder near its natural frequency. The observed acceleration amplitudes at the excited frequencies from these FFT diagrams are plotted against cutting speed for turning in Fig. 9a and for thread cutting in Fig. 10a. To analyze the relationship between chip instability 
and excitation of chatter, the primary and secondary chip serration frequencies vs. cutting speed relationships are plotted for turning in Fig. 9b and for thread cutting in Fig. 10b.

The following observations are made from the above figures:

The main vibration mode in the cases of turning and thread cutting are almost identical. The most significant vibrations in these cases correspond to the vibrations of the tool holder near its natural frequency (Fig. 7, 8 and Table 1). However, the magnitudes of the peak acceleration amplitude in the case of thread cutting are much lower (approximately 100 times) compared to those in turning. This is because of the very low cutting speeds employed in thread cutting $(17.3 \mathrm{~m} / \mathrm{min})$ as compared to turning $(350 \mathrm{~m} / \mathrm{min})$.
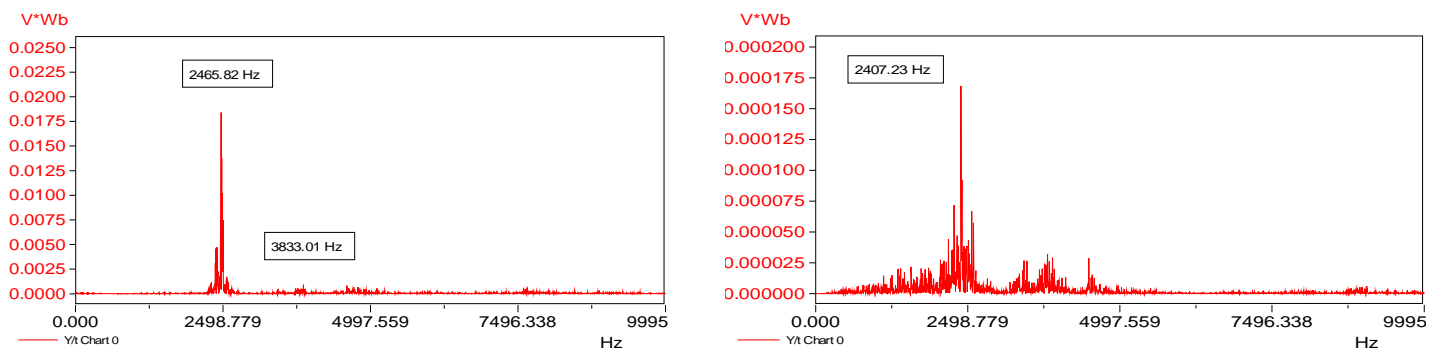

Fig. 7 (left): $\quad$ FFT power spectrum for turning at cutting speed of $350 \mathrm{~m} / \mathrm{min}$, depth of cut of $2 \mathrm{~mm}$ and feed rate of $0.1 \mathrm{~mm} /$ rot. Too holder overhang $=50 \mathrm{~mm}$

Fig. 8 (right): FFT power spectrum for thread cutting at cutting speed of $17.3 \mathrm{~m} / \mathrm{min}$, depth of cut of $1 \mathrm{~mm}$ and feed rate of $2.5 \mathrm{~mm} /$ rot. Tool holder overhang = $50 \mathrm{~mm}$.

The frequency of secondary and/or primary saw teeth formation increases almost linearly with cutting speed, but close to the natural frequency of the tool holder (or at approximately half of it, in the case of thread cutting) the rise in the frequency is either slowed down (Fig. 9b) remains constant (10b).

The overhang value (the natural frequency) of the tool holder has some influence on the primary chip serration frequency during turning due to mutual interaction, but the three curves are quite close (Fig. 9b).

Looking at the arrangement of the frequency of chip serration and the actual vibration frequency vs. cutting speed curves (Fig. 9b) and the amplitude vs. cutting speed plots (Fig. 9a) for turning, it is observed that the amplitude sharply increases when the chip frequency curve approach the corresponding natural frequency curve (at approximately $100 \mathrm{~m} / \mathrm{min}$ ).

In the case of thread cutting the primary and secondary chip serration frequencies are much lower than the tool holder's natural frequency. That is one of the reasons for low acceleration amplitude of the tool holder. However the amplitude is found to sharply increase as the main chip segmentation frequency (Freq 1), appearing at the chip edges (Fig. 4a-b), approaches the natural frequency of the workpiece, which is around $150 \mathrm{~Hz}$ (Table 2), and the second chip segmentation frequency (Freq 2), appearing at the middle 
section of the chip (Fig. 4a-b), is approximately half of the natural frequency of the tool holder (starting from $10.9 \mathrm{~m} / \mathrm{min}$ ). Over the cutting speed range from 10.9 to $17.3 \mathrm{~m} / \mathrm{min}$ the two chip frequencies are found to be constant, while the acceleration amplitude of the natural frequency mode of the tool holder increase sharply (Fig. $10 \mathrm{a}, \mathrm{b}$ ), similar to what was observed by Amin earlier [11].

Therefore, it can be concluded from the above observations that, the mechanisms of chatter formation in turning and in thread cutting are identical. However, chatter appears in the system during turning when the chip serration frequency approaches the natural frequency of the tool holder but in thread cutting when the frequency is half of the natural frequency of the same component.

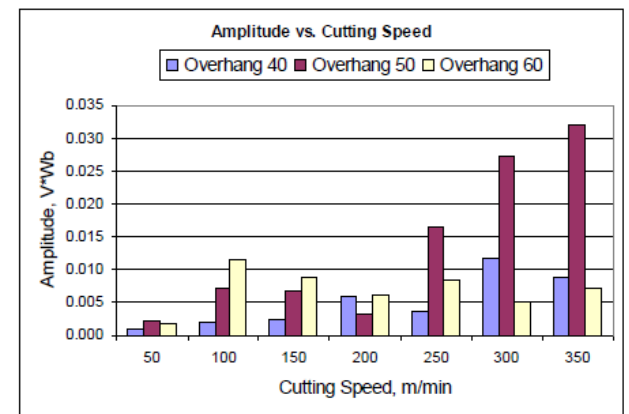

(a)

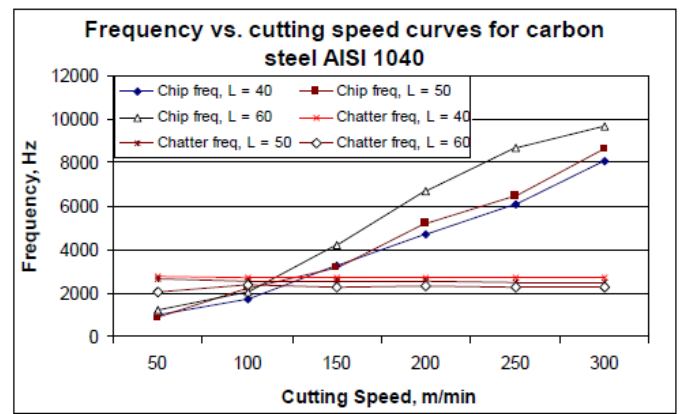

(b)

Fig. 9: The frequency vs. cutting speed curves (a) and vibration acceleration amplitude vs. cutting speed relationships (b) for carbon steel AISI 1040 during turning plotted for three overhang values of the tool. Feed rate and depth of cut were $0.1 \mathrm{~mm} /$ rot and $2 \mathrm{~mm}$ respectively.

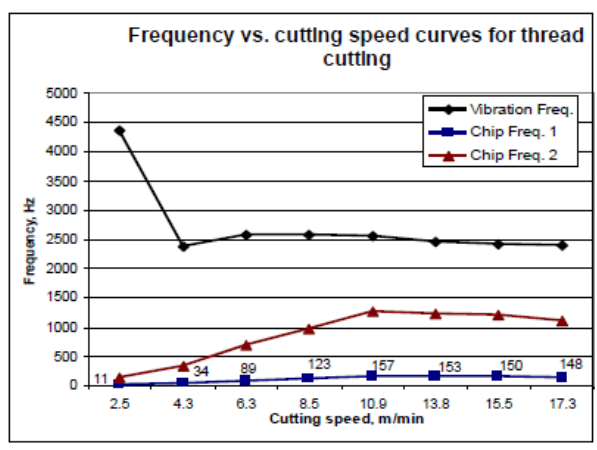

(a)

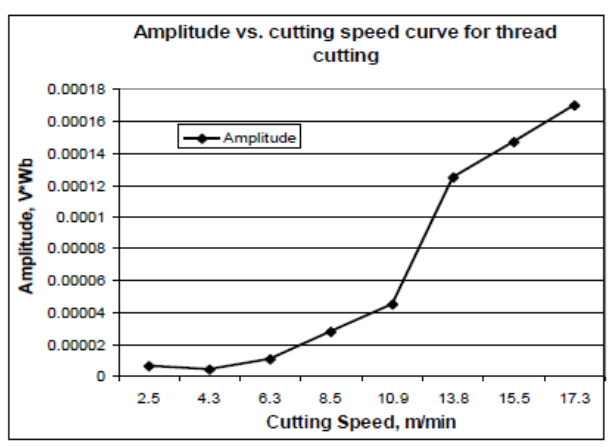

(b)

Fig. 10: The frequency vs. cutting speed curves (a) and vibration acceleration amplitude vs. cutting speed relationships (b) for thread cutting plotted for tool overhang value of 50 $\mathrm{mm}$. Pitch $=6.5 \mathrm{~mm}$ (MBS7X) and depth of cut: $1 \mathrm{~mm}$. Work material: carbon steel AISI 1040 .

\subsection{Relationship between Secondary/Primary Saw Teeth Frequency and Vibration/Chatter Frequency in End Milling}

The vibrations were recorded during machining using the data acquisition system in the time domain and the then the Fast Fourier Transformation was performed. A sample of 
FFT power spectrum is shown in Fig. 11, which indicates that there are mainly two excited frequency ranges in which high acceleration amplitudes are recorded. The frequency ranges are: $2500-2700 \mathrm{~Hz}$ and $4000-4700 \mathrm{~Hz}$, which are close to the natural frequencies of the tool and the spindle respectively (Table 2). There is also some amplification in the frequency ranges of 400-600 and 2000-2400 Hz, but the acceleration amplitudes at these two frequency ranges are one order lower compared to that in the first two ranges. Figure 12 shows the changes in the frequency of secondary saw teeth formation (Fig. 5, 6) with cutting speed. The method of calculation of the saw teeth frequency was discussed in the methodology section.
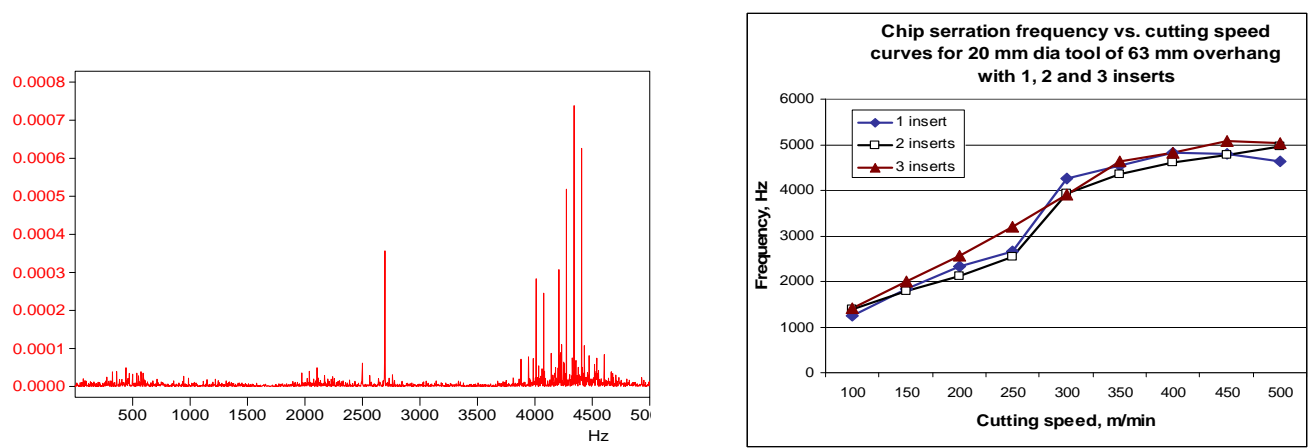

Fig. 11 (left): FFT power spectrum for end milling of steel AISI 1040 at the cutting speed $200 \mathrm{~m} / \mathrm{min}$ ( $2 \mathrm{~mm}$ depth of cut, $0.1 \mathrm{~mm} /$ tooth feed, $3 \mathrm{insert})$. Tool diameter $=20 \mathrm{~mm}$ and overhang $=63 \mathrm{~mm}$.

Fig. 12 (right): Frequency vs. cutting speed curves for 1, 2 and 3 inserts for end milling $(\mathrm{DOC}=1 \mathrm{~mm}$, Feed $=0.1 \mathrm{~mm} /$ tooth .

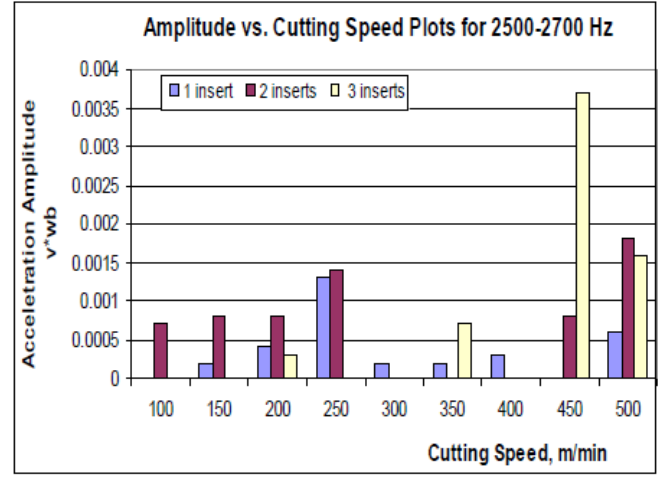

(a)

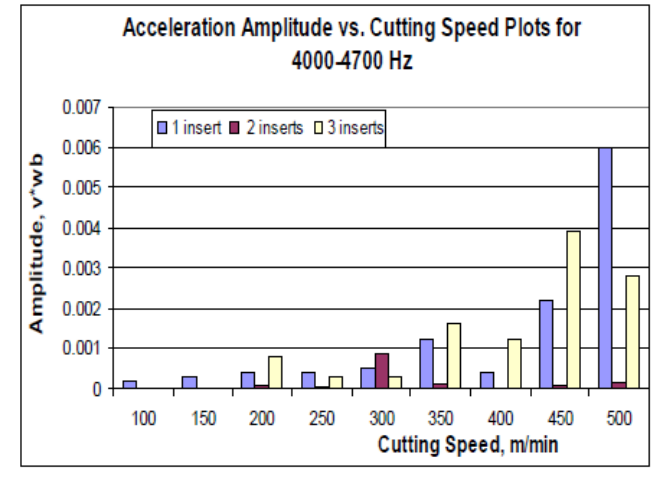

(b)

Fig. 13: Bar charts of acceleration amplitude vs. cutting speed: (a) for tool vibration $(2500-2700 \mathrm{~Hz})$ and (b) for spindle vibrations; for 1, 2 and 3 inserts for end milling of steel AISI 1040. $(\mathrm{DOC}=1 \mathrm{~mm}$, Feed $=0.1 \mathrm{~mm} /$ tooth, Tool diameter $=20 \mathrm{~mm}$ and overhang $=63 \mathrm{~mm}$ )

After careful comparison of the frequency vs. cutting speed curves (Fig. 12) with the two amplitude vs. cutting relationships (Fig. 13 a-b); the following observations were made: 
When the frequencies of secondary serrated teeth approach the natural frequency of the tool $(2540 \mathrm{~Hz})$ or that of the spindle $(4700 \mathrm{~Hz})$, there is a tendency of flattening of the frequency vs. cutting speed curves (Fig. 12) over a range of cutting speed, similar to that in turning and thread cutting, as discussed in the previous section (Fig. 9b, 10b).

In the frequency range of the tool (Fig. 12), acceleration amplitudes are found to increase as the chip serration frequency get close to and crosses the natural frequency level of the tool in the cutting speed range of 100-250 m/min (Fig. 13a).

In the spindle's natural frequency range no severe vibrations are observed up to the cutting speed of $250 \mathrm{~m} / \mathrm{min}$ because the chip frequency in this cutting speed range is much below the natural frequency range of the spindle (Fig. 12, 13b), but the amplitude starts to increase from $300 \mathrm{~m} / \mathrm{min}$ when the chip frequency approaches the natural frequency of the spindle for all the insert combinations. The double insert tool is found to be very stable in the entire cutting speed range with respect to the spindle vibrations except at the speed of $300 \mathrm{~m} / \mathrm{min}$. The peak for single insert tool is at $500 \mathrm{~m} / \mathrm{min}$ and that for the double insert tool is at $450 \mathrm{~m} / \mathrm{min}$.

\section{CONCLUSION}

The following conclusions have been drawn from the work:

1. The chips produced during turning and end milling, exhibit regularly spaced secondary saw teeth along the free edge of the chip. In the case of thread cutting these secondary saw teeth appear along both the edges of the chip. The primary and the secondary saw teeth have definite formative cycles and their frequencies increase with the cutting speed.

2. Apart from the discreteness of the chip formation process, the machine toolworkpiece-fixture system has various natural frequencies, some of which play prominent role in chatter formation. It has been found that the natural frequency of the tool holder plays a prominent role in generating vibration and chatter during turning and thread cutting. In end milling, there are two components responsible for chatter; they are the tool and the spindle. However, the spindle has been identified as the main "weak component", since high amplitudes of vibration of the entire machine occurs when this component starts vibrating with high amplitude at frequencies close to its natural frequency.

3. It has been also found that chatter or vibration with high amplitude appears in the system during turning, thread cutting and end milling when the frequency of chip formation instability becomes approximately half (as in thread cutting), equal to or integer multiple of the prominent natural frequency (ies) of the system component(s) (as in turning and end milling). Hence there is a common mechanism of formation of chatter in these different machining processes. Chatter arises in the system as a result of resonance caused by the interaction of secondary (primary) saw teeth frequency and the natural frequencies of the prominent system components.

4. The prominent system component responsible for chatter in lathe operations is the tool holder in the practically applied cutting speed range and in end milling the two the two prominent system components are the tool (at relatively lower cutting speeds) and of the spindle (at relatively higher speeds). In end milling the most severe chatter is 
attributed to the spindle, especially when simultaneous chatter of the spindle and the tool are excited.

5. The phenomenon of chatter in the absence of chatter marks from earlier cut in the case of thread cutting that 'Regenerative Effect' is not the cause of chatter.

\section{ACKNOWLEDGEMENTS}

The authors would like to acknowledge the financial support received from the Ministry of Higher Education, Malaysia in conducting this research work and the Research Management Centre IIUM for overall management of the projects. Support of the undergraduate and graduate students and lab technicians in the work are also recorded with deep appreciation.

\section{REFERENCES}

[1] Taylor F W, The Art of Metal Cutting, USA, (1922).

[2] Kuznetsov V D, Fizika Rezania Trenia Metallov e Kristalov, Moscow, Nayka, (1977) p 310.

[3] Kudinov V A, Dynamics of Machine Tools Moscow: Publication of Machine Building, 1965, p 358.

[4] Shteinberg I C, Removal of Chatter Appearing During the Metal Cutting Process on Lathe Machine, Moscow: Publication of Machine Building, (1976).

[5] Doi S, On the Chatter Vibrations of Lathe Tools, Memoirs of the Department of Mechanical Engineering, Nagoya University, 5, (1953) p 179.

[6] Doi S and Kato S, Chatter Vibrations of Lathe Tools, Trans. Amer. Soc. Mech. Eng., 78, (1953) p 1073.

[7] Kato S, Theoretical Research on Chatter Vibration of Lathe Tools, Memoirs of the Department of Mechanical Engineering, Nagoya University, (1958) p 117.

[8] Smith J D, The Dynamic Cutting of Metals, Ph.D. Thesis, University of Cambridge, (1962).

[9] Smith J D, Tobias S A, The Dynamic Cutting of Metals, Int. J. Machine Tool Design and Res., 1, (1961) p 283.

[10] Amin A K M N, Investigation of the Laws Governing the Formation of Chatter during Metal Cutting Processes and their Influence on Tool Wear, Ph.D. thesis, Georgian Polytechnic Institute, Georgia, (1982) p 276.

[11] Amin A K M N, Investigation of the Mechanism of Chatter Formation during the Metal Cutting Process, Mech. Eng. Res. Bulletin, 6/1, (1983) pp 11-18.

[12] Amin A K M N, Influence of the Characteristics of Machine-Tool-Fixture-Work (MTFW) System on Chatter, Journal of the Institute of Engineers Bangladesh, 13/4, (1985) pp 9-16.

[13] Israd H J, Investigations in Machine Tool Chatter in an End Milling Operation on a Vertical Machining Center, M.Sc. Thesis, International Islamic University of Malaysia, Malaysia, (2002) p 156.

[14] Amin A K M N, Abdelgadir M M, The Effect Of Preheating Of Work Material on Chatter during End Milling of Medium Carbon Steel Performed on a Vertical Machining Center (VMC), ASME Journal of Manufacturing Science and 
Engineering, Transactions of the ASME, USA, Vol. 125, Nov. (2003) pp 667-680.

[15] Amin A K M N, Abdelgadir M, The Effect of Preheating of Work Material on Chatter of VMC and Machinability of Work Materials, Proceedings of the Second World Engineering Congress, Kuching, Malaysia, (2002) pp 215-220.

[16] Altintas Y and E. Budak. Analytical prediction of chatter stability in milling - part 1: Application of the general formulation to common milling systems. Journal of Dynamic Systems, Measurement and Control, Transactions of the ASME, 120:2330, 1998.

[17] Altintas, Y \& Budak, E. (1995), Analytical prediction of stability lobes in milling. Ann. CIRP 44, 357-362.

[18] Altintas, Y. and Budak, E. (1995). "Analytical Prediction of Stability Lobes in Milling,"

[19] Altintas, Y., (1999), Analytical Prediction of Stability Lobes in ball End milling, Trans. ASME, Vol. 121, pp. 586-592.

[20] Mann B.P., T. Insperger, P.V. Bayly and G. Stépán, 2003, Stability of up-milling and down-milling. Part 2. Experimental verification, I.J. MT M 43, pp. 35-40.

[21] Insperger, T. and Stépán, G. (2001). "Semi-discretization of Delayed Dynamical Systems," Proceedings of DETC '01 ASME 2001 Design Engineering Technical Conference and Computers and Information in Engineering Conference Pittsburgh, PA,

[22] Insperger, T., and Stépán, G. (2002). "Semi-discretization Method for Delayed Systems," International Journal of Numerical Methods in Engineering, Vol. 55, pp. 503-518.

[23] Long, X.H., and Balachandran, B. (2004). "Milling Model with Variable Time Delay," Proceedings of IMECE 2004 ASME International Mechanical Engineering Congress. 